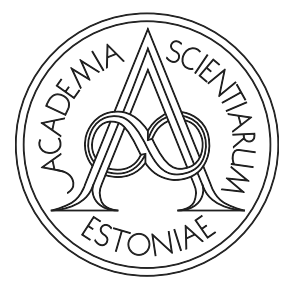

Proceedings of the Estonian Academy of Sciences, $2021,70,4 S, 326-332$

https://doi.org/10.3176/proc.2021.4S.03

Available online at www.eap.ee/proceedings

VISION

SCIENCE

\title{
Comparative assessment of spatial perception in augmented reality depending on the consistency of depth cues
}

\author{
Linda Krauze ${ }^{\mathrm{a} *}$, Tatjana Pladere ${ }^{\mathrm{a}}$, Roberts Zabels ${ }^{\mathrm{b}}$, Rendijs Smukulis ${ }^{\mathrm{b}}$, Viktorija Barkovska ${ }^{\mathrm{a}}$, Vita \\ Konosonoka ${ }^{a}$, Ibrahim Musayev ${ }^{\mathrm{a}}$, Aiga Svede ${ }^{\mathrm{a}}$ and Gunta Krumina ${ }^{\mathrm{a}}$ \\ a Department of Optometry and Vision Science, Faculty of Physics, Mathematics and Optometry, University of Latvia, Jelgavas iela 1, \\ 1004 Riga, Latvia \\ ${ }^{\mathrm{b}}$ LightSpace Technologies, Ziedleju 1, 2167 Marupe, Latvia
}

Received 1 November 2020, accepted 18 February 2021, available online 20 September 2021

(C) 2021 Authors. This is an Open Access article distributed under the terms and conditions of the Creative Commons AttributionNonCommercial 4.0 International License (http://creativecommons.org/licenses/by-nc/4.0/).

\begin{abstract}
Discrepancies between depth cues (accommodation and vergence) is one of the major issues caused in a stereoscopic augmented reality at close viewing distances. It adversely affects not only user comfort but also spatial judgements. Images with consonant cues at different distances have become available due to the implementation of multifocal architecture in the head-mounted displays, although its effect on spatial perception has remained unknown. In this psychophysical study, we investigated the effects of consonant and conflicting depth cues on perceptual distance matching in the stereoscopic environment of augmented reality using a head-mounted display that was driven in two modes: multifocal mode and single-focal plane mode. The participants matched the distance of a real object with the images projected at three viewing distances $(45 \mathrm{~cm}, 65 \mathrm{~cm}$, and $115 \mathrm{~cm})$. As a result, no significant differences in the accuracy of spatial perception were shown depending on the consistency of cues. However, the perceptual tasks were completed faster when the depth cues were consonant. Overall, the results of our experiment show that consonant depth cues facilitate faster judgements on spatial relations between real objects and images projected in augmented reality, which can be achieved when images are displayed using multiple depth planes in the head-mounted display. Further technological advancements might be required to improve the accuracy of spatial judgements in augmented reality.
\end{abstract}

Key words: visual perception, augmented reality, depth cues, distance matching, head-mounted display, multiple planes.

\section{INTRODUCTION}

Recent developments in three-dimensional image display technologies for augmentation of reality have led to a growing interest towards spatial perception research. Research in this domain aims to describe the quality of viewing experience and discover potential benefits and limitations of new visualisation approaches intended for use in professional capacities. Precise perception and interpretation of digital spatial information is crucial for decision making in many professional areas, such as healthcare, education, aerospace, and defence.

\footnotetext{
* Corresponding author, linda.krauze@lu.lv
}

Human spatial perception relies on a combination of multiple information sources - the so-called depth cues [1]. The differences in perception are related to the availability and weight of depth cues. Binocular depth cues (retinal disparity and vergence) ensure the most accurate judgements about spatial relations between objects in the near field, although their contribution to spatial perception decreases with an increase in viewing distance [1,2]. Besides the availability of depth cues, their consistency plays an important role. For instance, accommodation and vergence cues provide the same information about the depth of an object in natural viewing [3].

Today, there are different types of display systems used for the three-dimensional presentation of information 
in augmented reality; however, most of them do not provide consistent depth cues. Typically, one focal plane is used in the stereoscopic head-mounted display [4,5] and as a consequence, the accommodation responds differently to the stereoscopic images than it does in natural viewing. Namely, the eyes should accommodate on the screen plane and converge at the depth of the displayed image $[6,7]$. Thus, a vergence-accommodation conflict occurs.

Previous studies on the response of the visual system to stereoscopic images have identified the vergenceaccommodation conflict as one of the most crucial issues affecting user comfort and performance [8-10]. In general, a slight mismatch between depth cues up to $0.3-0.4 \mathrm{D}$ has been demonstrated to be tolerable by individuals, and conflicts larger than $0.4 \mathrm{D}$ have been suggested to cause discomfort [11]. Moreover, the vergence mechanism becomes slower when a vergence-accommodation conflict is present [12], and the response of the oculomotor system is inconsistent [13]. However, the findings describing spatial perception are controversial. Some studies showed that spatial judgements were not affected even when conflicts ranging from 1.0 to $4.0 \mathrm{D}$ were induced [14,15], whereas other studies reported that the induced vergenceaccommodation mismatch was adversely reflected in the judgement of depth [5,9]. In particular, the just noticeable difference in depth increased for stereoscopic images in comparison to that for real objects [9]. Therefore, improvements are required to eliminate such user performance problems $[8,16]$.

Most of the research on spatial perception in augmented reality has been performed using single-focal plane headsets $[4,17]$. When only one display plane with the focal length of around $2 \mathrm{~m}$ is employed, the effects of the vergence-accommodation conflict are inevitable at close viewing distances. Despite the availability of display architectures that are developed to mitigate or eliminate this issue [18-20], it has remained unknown whether its implementation is reflected in the accuracy and temporal aspects of spatial perception in augmented reality [5]. In this respect, the aim of our study was to assess the effect of the consistency of depth cues on perceptual distance matching in augmented reality using a head-mounted display with multifocal architecture.

\section{METHOD}

In this study, we investigated the effects of two conditions, i.e., the consonant cues condition and the conflicting cues condition, on perceptual distance matching in a stereoscopic environment of augmented reality using a LightSpace Technologies IG-1000 headset prototype. The variability in the vergence and accommodation cues was achieved by switching between a multifocal and singlefocal plane mode (when deactivating all but one focal plane). Thus, both conditions were realised by using the same headset - ensuring the identical attributes of the conveyed images, i.e., the field of view, image brightness, image refresh rate and colour balance.

\section{Participants}

A total of 17 individuals ( 7 males, 10 females; mean age: $27 \pm 2$ years) participated in the study. The visual functions of each participant were tested before completing the task to assure sufficient visual discrimination abilities. The participants met the following criteria: binocular near visual acuity 1.0 or better (in decimal units); near stereo acuity of $40 \mathrm{~s}$ of arc or better (Titmus stereo test); binocular accommodative facility of $6 \mathrm{cpm}$ (cycles per minute) or more ( $+/-2.00 \mathrm{D}$ lens flipper); vergence facility of $7 \pm 3 \mathrm{cpm}$ ( $8 \Delta$ base-in/ $8 \Delta$ base-out prism flipper); near point of convergence from $6 \mathrm{~cm}$ to $10 \mathrm{~cm}$, recovery point of convergence up to $15 \mathrm{~cm}$; and near and distance phoria are compensated in accordance with the Sheard criterion (i.e., heterophoria should be less than half the opposing fusional vergence reserves).

The study was approved by the Ethics Committee of the University of Latvia, and was conducted in accordance with the principles of the Declaration of Helsinki.

\section{Apparatus}

The LightSpace Technologies IG-1005 prototype headset was used in the study. It is a stereoscopic augmented reality display device with four focal planes optically located at $0.45 \mathrm{~m}, 0.65 \mathrm{~m}, 1.15 \mathrm{~m}$, and $5.30 \mathrm{~m}$.

The display utilises switchable optical diffuser elements to separate the physical display planes [19]. Diffuser elements are driven between a highly light transparent state and a highly light scattering state (screen mode). At any given moment in time, only one diffuser element is in the screen mode, while the rest are transparent. In the transparent state, the diffuser elements allow more than $95 \%$ of visible light to pass, a haze value is less than $0.2 \%$. Due to the optical properties of diffuser elements, all focal planes are identical from the standpoint of image metrics - no noticeable differences can be observed. The image refresh rate is $60 \mathrm{~Hz}$.

\section{Study design}

The experimental setup consisted of a motorised linear stage with a sliding carriage (see Fig. 1). A thin metal pole was mounted on the top of the carriage, whereas a physical object was mounted on the top of the pole. The participant could move the physical object in two 


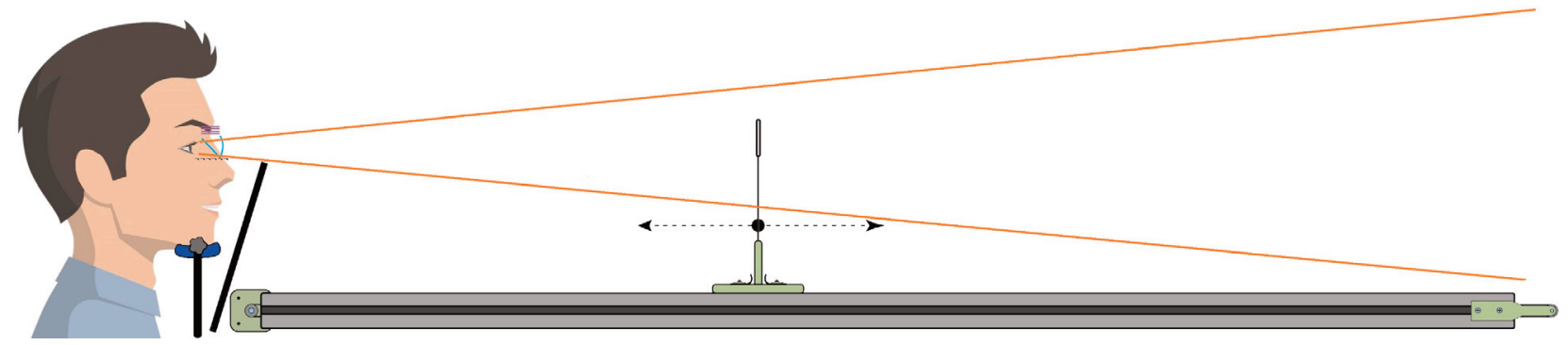

Fig. 1. The schematic of the experimental setup. The participant with a headset sat in front of the linear stage (total length $-2.4 \mathrm{~m}$ ). The shading plane was used to block the view of the linear stage. The linear stage was equipped with the sliding carriage, which held a physical pointer on a thin pole.

directions - closer or further away with the help of the buttons "up" and "down" on the remote control. The smallest achievable change of position of the physical object on the rail was $1 \mathrm{~mm}$. The participant sat facing the rail and wore the headset. In order to keep the projection centred and the participant's eyes vertically aligned throughout all trials, a chin rest was used to minimise head movements. The fixation of head position was also required to ensure that the participant did not see the rail and could not use its appearance for additional depth cues.

Prior to the task, each participant underwent the display calibration procedure. First, the interpupillary distance of the participant was determined. Then, this value was used for the image rendering engine as the rendering parameter. A calibration image was shown through the headset to the participant on each focal plane separately. In consonance with the output of the calibration image, the physical stimulus on the linear stage was set to the corresponding distance of the given focal plane. Similar to the procedure implemented in [21], the participant was asked to adjust the digital image offset for two parts of a calibration image while looking at the physical stimulus. The adjustments were performed until the participant saw the calibration image as the symmetrical cross. The calibration steps were repeated two times for all focal planes to test the consistency of the obtained results.

Next, the perceptual distance matching task followed. A two-dimensional image was demonstrated at three different distances from the participant: $45 \mathrm{~cm}, 65 \mathrm{~cm}$, and $115 \mathrm{~cm}$, which corresponded to $2.2 \mathrm{D}, 1.5 \mathrm{D}$, and $0.9 \mathrm{D}$, respectively. Eight repetitions of the matching task were performed at each image distance. We tested two viewing conditions. In the consonant cues condition, the images were demonstrated at the focal distances of planes that were consistent with the actual image distances. In the conflicting cues condition, only the display plane with the focal distance at $5.3 \mathrm{~m}(0.2 \mathrm{D})$ was employed. Thus, the image distances did not correspond to the focal distances, and the vergence-accommodation conflict of $2.0 \mathrm{D}, 1.3 \mathrm{D}$, and $0.7 \mathrm{D}$ was induced.
The initial session included two repetitions of tasks per actual image distance to familiarise the participants with the visual stimulus, task, and setup. Then, the experiment session followed.

The participant was shown two different images in each eye by using the headset. Provided that the fusion reserves ensure proper merging of two images, the participant saw a single image with one star in the centre of a rectangular arch and circles at the corners of it. The contours of all visual stimuli were white. To avoid the potential effect of suppression on spatial judgements, different circles were demonstrated to each eye (i.e., each eye was shown a different position and number of circles, ensuring that the correct answer to the number of circles demonstrated can only be given under the binocular condition) (see Fig. 2). The maximum number of circles was four (in total for both eyes). The total number of
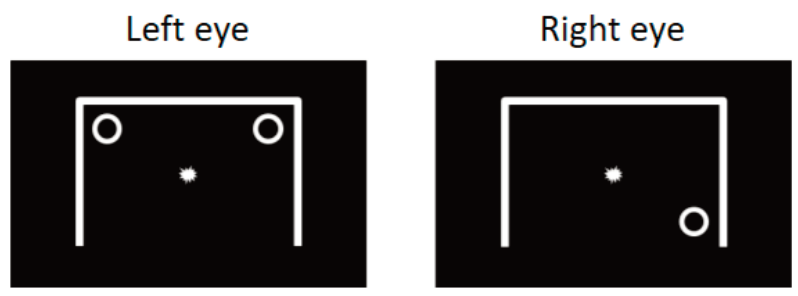

Binocular percept

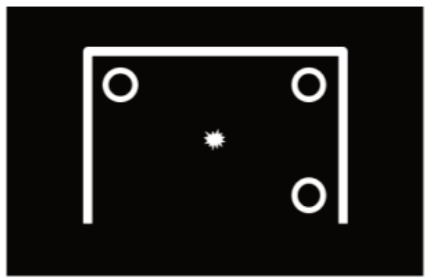

Fig. 2. Example of the demonstrated stimuli for each eye separately and the resultant binocular percept if both images were fused properly. To detect the monocular suppression, different circles were demonstrated to each eye. A circle and a rectangular arch were used to stimulate binocular fusion. 
circles at the beginning of the task was chosen in random order (from 2 to 4 ). The possible locations were as follows: in the upper right corner, in the upper left corner, in the lower right corner and in the lower left corner. The size of the elements was as follows: star $-0.5^{\circ}$ diameter, rectangular $\operatorname{arch}-4.0^{\circ} \times 3.5^{\circ}$, circle $-0.6^{\circ}$ diameter.

If the participant saw one circle and one frame, then they responded with the number of circles perceived in the trial. The time countdown began when the response was submitted. The experiment was not time constrained, however, the participants were instructed to complete the task as accurately and fast as possible. The participant moved the pointer to align with the position of the projected star. When the participant considered the alignment to be correct, they reported it to the experimenter and closed their eyes until the next instruction. As soon as the response was given, the time countdown was stopped, and the value of the matched distance was collected. Next, the experimenter changed the position of the physical pointer to one of the predefined initial distances $( \pm 5, \pm 10, \pm 15$, and $\pm 20 \mathrm{~cm}$ from the actual image distance), the sequence of which was randomly varied among trials and viewing conditions. Then, the experimenter switched on the next trial, asked the participant to open their eyes, and the next trial took place. Each participant completed 2 (cues conditions) $\times 3$ (image planes $) \times 8$ (trials $)=48$ trials of perceptual distance matching, which yielded 816 total trials in the analysis.

\section{Data analysis}

Spatial perception data showing how accurately and fast the participants matched the distance of the demonstrated stimulus were obtained. The experiment had two independent variables: the cues condition (consonant cues and conflicting cues) and the actual image plane $(45 \mathrm{~cm}, 65 \mathrm{~cm}$, and $115 \mathrm{~cm}$ ). Therefore, a repeated-measures ANOVA was applied as the analysis method to determine the influence of factors on the dependent variables which were the matched distance, absolute error, and task completion time. The size of statistically significant effects was estimated by generalised eta squared $\left(\eta_{G}^{2}\right)$ indices [22].

\section{RESULTS}

The average results of all participants in terms of the accuracy of perceptual distance matching in augmented reality are summarised in Table 1.

Overall, the average matched distance values were close to the actual ones when the perceptual distance matching was performed for images at the closest tested distances. The inter-participant variability grew and the accuracy of judgements decreased with an increase in the image distance from the observer, which was reflected in the absolute errors. On average, the absolute errors differed two times, comparing the accuracy of distance matching at $45 \mathrm{~cm}$ and $115 \mathrm{~cm}$. Nevertheless, the statistical significance was not reached when evaluating the effect of the cues condition $\left(F_{1,16}=1.40, p=0.25, \eta^{2}{ }_{G}\right.$ $=0.030)$ and the interaction of two factors $\left(F_{1.4,22.1}=1.29\right.$, $\left.p=0.28, \eta^{2}{ }_{G}=0.014\right)$ on the absolute errors. However, the errors grew considerably with an increase in the actual image distance $\left(F_{1.3,20.3}=22.03, p<0.01, \eta_{G}^{2}=0.183\right)$. The effect size was large according to Cohen's scale [23]. In general, the image distances were overestimated more often than underestimated.

To explore the temporal aspects, the task completion time was analysed in addition to the accuracy of perceptual judgements. The average results are shown in Fig. 3.

For the perceptual task completion time, the significant effect of the cues condition was observed $\left(F_{1,50}=4.46, p<0.05, \eta_{G}{ }_{G}=0.153\right)$. According to Cohen's scale [23], there was a large effect size of the cues condition on the task completion time. The perceptual matching tasks were completed considerably faster when the depth cues were consonant. The largest difference was revealed for images at the closest tested distance. However, no significant differences were observed in regard to the actual image planes $\left(F_{1,50}=0.57, p=0.56\right.$, $\left.\eta_{G}^{2}=0.012\right)$. Moreover, the interaction between two factors did not reach significance $\left(F_{1,50}=0.18, p=0.83\right.$, $\left.\eta_{G}^{2}=0.004\right)$. Generally, the task completion time increased slightly with an increase in the viewing distance in the consonant cues condition.

Table 1. Means and standard deviations of the accuracy of perceptual distance matching in the consonant cues condition and the conflicting cues condition

\begin{tabular}{l|c|c|c|c}
\hline \multirow{2}{*}{ Actual distance } & \multicolumn{2}{|c|}{ Consonant cues } & \multicolumn{2}{c}{ Conflicting cues } \\
\cline { 2 - 5 } & Matched distance & Absolute error & Matched distance & \multirow{2}{*}{ Absolute error } \\
\hline $45 \mathrm{~cm}$ & $45.9-3.2 \mathrm{~cm}$ & $2.3-1.8 \mathrm{~cm}$ & $47.0-4.4 \mathrm{~cm}$ & $2.6-3.7 \mathrm{~cm}$ \\
$65 \mathrm{~cm}$ & $65.8-3.2 \mathrm{~cm}$ & $2.5-1.5 \mathrm{~cm}$ & $66.8-5.2 \mathrm{~cm}$ & $3.4-3.5 \mathrm{~cm}$ \\
$115 \mathrm{~cm}$ & $114.3-7.7 \mathrm{~cm}$ & $4.8-4.1 \mathrm{~cm}$ & $117.1-9.3 \mathrm{~cm}$ & $7.4-5.9 \mathrm{~cm}$
\end{tabular}




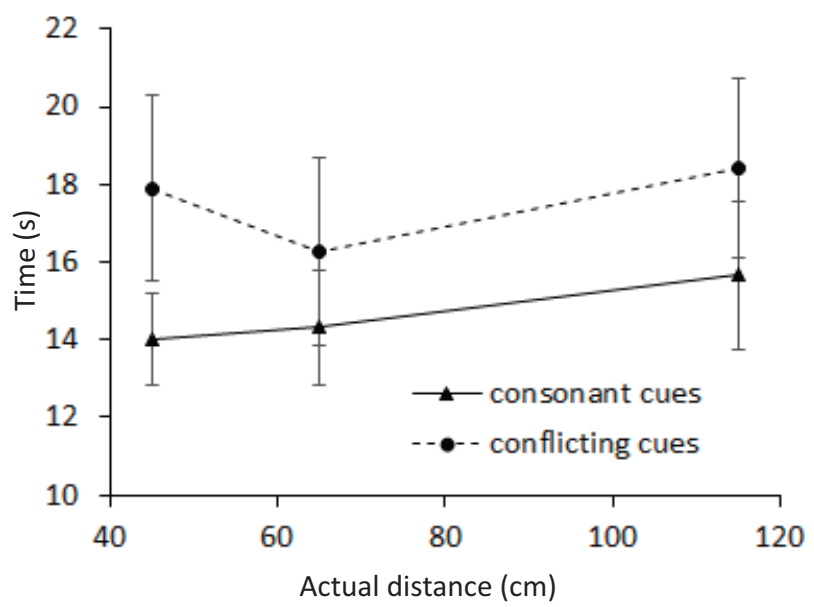

Fig. 3. Mean task completion time depending on the actual image distance in the consonant cues and conflicting cues conditions (error bars represent standard errors).

\section{DISCUSSION}

In this study, the perceptual distance matching task was used specifically for the purpose of evaluating spatial perception in augmented reality depending on the depth cues in a comparative manner. Moreover, the implementation of the physical pointer allowed us to assess the spatial relationship between the projected images and physical objects. For a reliable comparison, the multifocal augmented reality display with discrete focal planes was driven in the multifocal mode and single-focal plane mode.

Our study showed considerable differences in the accuracy of perceptual distance matching in regard to the distance of displayed images in a range of $45 \mathrm{~cm}$ to $115 \mathrm{~cm}$. Overall, the participants could successfully match the real objects and the augmented reality images in depth at close viewing distance. However, the absolute errors grew with an increase in image distance. Similar findings were reported in the studies on perceptual judgements not only for augmented reality images [24] but also for real objects [2]. Generally, the accuracy of judgements on spatial relations between objects is high at close viewing distances and drops with the increase in distance [2,25]. In natural viewing, spatial perception is not homogeneous, and the perceived locations of objects do not often coincide with their actual positions - this is known as anisotropy of spatial perception [25]. However, the misjudgements of distances can be amplified when images are presented in a stereoscopic way $[9,26]$. In general, the nearfield distances are expected to be overestimated in the presence of the vergence-accommodation conflict [26-28]. Actually, individuals can make inaccurate judgements of both types (overestimating and underestimating distances) for the same viewing conditions [29]. In our study, the dominance of overestimation could be linked to the technique of perceptual matching. Specifically, the overestimation was shown to be associated with the use of physical pointers instead of virtual pointers [28]. Furthermore, our findings did not reveal any considerable impact of the vergence-accommodation conflict on the average accuracy of distance matching. This might mean that individuals could tolerate the amount of vergence-accommodation conflict when matching the distance between the real object and the presented image. Further advancements in the quality of images might lead to a more pronounced effect of conflicting depth cues on the accuracy of spatial judgements.

The assessment of the consistency of depth cues on perceptual distance matching also showed that the tasks were completed faster when the images contained consonant information about depth, especially at close viewing distance. This has allowed us to assume that decisions about spatial relations between projected images and real objects were less time consuming than in the conflicting cues condition. The largest difference was observed when the image was displayed at $45 \mathrm{~cm}$ distance, indicating that the image distance was more difficult to be estimated when the depth cues were in conflict.

The user experience and performance can differ when the image display is capable of conveying more consonant depth cues, for instance, by providing better correspondence of accommodation and vergence cues due to the presentation of visual stimuli on different depth planes. In the field of human-computer interaction, there is an ongoing debate about how to improve user experience and performance in stereoscopic augmented reality [5,19]. As far as augmented reality displays are expected to be used not only for entertainment applications but also for professional purposes [30-32], the accuracy of spatial judgements is of high importance. However, most conventional augmented reality displays do not generate images with consonant accommodation and vergence cues [4,5]. When planning further improvements of alternative headmounted displays, one should remember that user performance is influenced by both the quality of the information visualisation and the specifics of human visual perception. Our results showed that the matched distances of real objects and displayed images differed from the actual ones even when accommodation and vergence cues were consonant in augmented reality images. Thus, our work has indicated the demand for further advancements. The accuracy of perceptual judgements might be further improved by advancing the quality of displayed images [33], ensuring more consonant depth cues $[1,24]$, and developing meaningful visual training for future users [29]. 


\section{CONCLUSIONS}

Spatial perception in augmented reality was investigated using a stereoscopic see-through head-mounted display. For the first time, it was assessed how the consistency of depth cues and the absence of it affected perceptual distance judgements in a comparative manner. In conclusion, no considerable differences were shown in the accuracy of judgements depending on the consistency of cues. Moreover, our results demonstrated that the consistency of depth cues facilitated faster completion of perceptual tasks in augmented reality, especially at the closest image viewing distance. These findings indicate that the implementation of multifocal architecture in the headset can improve the user performance in regard to spatial judgements between real objects and displayed images. Further studies should explore the potential effects of individual differences in the visual functions on perceptual judgements in augmented reality. These may expand the understanding of human factors contributing to spatial perception in respect of the novel display systems and predict user acceptance.

\section{ACKNOWLEDGEMENTS}

This work was part of the research project supported by LightSpace Technologies ("Evaluation of volumetric display's 3D image effect on human visual system", Project No. ZD2019/20807). It was also supported by the European Regional Development Fund ("Development of a compact, high-brightness laser image projection system for application in volumetric 3D displays", Project No. 1.1.1.1/18/A/179). The publication costs of this article were partially covered by the Estonian Academy of Sciences.

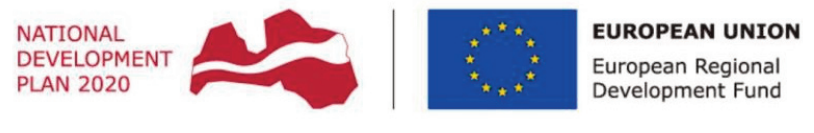

INVESTING IN YOUR FUTURE

\section{REFERENCES}

1. Cutting, J. E. and Vishton, P. M. Perceiving layout and knowing distances: the integration, relative potency, and contextual use of different information about depth. In Handbook of Perception and Cognition: Perception of Space and Motion, vol. 5 (Epstein, W. and Rogers, S., eds). Academic Press, San Diego, CA, 1995, 69-117.

2. Viguier, A., Clément, G. and Trotter, Y. Distance perception within near visual space. Perception, 2001, 30(1), 115-124.
3. Peli, E. Optometric and perceptual issues with head-mounted displays. In Visual Instrumentation: Optical Design and Engineering Principles (Mouroulis, P., ed.). McGraw-Hill, New York, NY, 1999.

4. Condino, S., Carbone, M., Piazza, R., Ferrari, M. and Ferrari, V. Perceptual limits of optical see-through visors for augmented reality guidance of manual tasks. IEEE Trans. Biomed. Eng., 2020, 67(2), 411-419.

5. Peillard, E., Itoh, Y., Normand, J.-M., Argelaguet, F., Moreau, G. and Lécuyer, A. Can retinal displays improve spatial perception in augmented reality? In Proceedings of the 2020 IEEE International Symposium on Mixed and Augmented Reality, Porto de Galinhas, Brazil, November 913, 2020. IEEE.

6. Hoffman, D. M., Girshick, A. R., Akeley, K. and Banks, M. S. Vergence-accommodation conflicts hinder visual performance and cause visual fatigue. J. Vis., 2008, 8(3), 33.

7. Howarth, P. A. Potential hazards of viewing 3-D stereoscopic television, cinema and computer games: A review. Ophthalmic Physiol. Opt., 2011, 31(2), 111-122.

8. Watt, S. J., Akeley, K., Ernst, M. O. and Banks, M. S. Focus cues affect perceived depth. J. Vis., 2005, 5(10), 7.

9. Naceri, A., Moscatelli, A. and Chellali, R. Depth discrimination of constant angular size stimuli in action space: role of accommodation and convergence cues. Front. Human Neurosci., 2015, 9, 511.

10. Wee, S. W., Moon, N. J., Lee, W. K. and Jeon, S. Ophthalmological factors influencing visual asthenopia as a result of viewing 3D displays. Br. J. Ophthalmol., 2012, 96(11), 1391-1394.

11. Shibata, T., Kim, J., Hoffman, D. M. and Banks, M. S. The zone of comfort: Predicting visual discomfort with stereo displays. J. Vis., 2011, 11(8), 11.

12. Vienne, C., Sorin, L., Blondé, L., Huynh-Thu, Q. and Mamassian, P. Effect of the accommodation-vergence conflict on eye movements. Vision Res., 2014, 100, 124-133.

13. Liversedge, S. P., Holliman, N. S. and Blythe, H. I. Binocular coordination in response to stereoscopic stimuli. In Stereoscopic Displays and Applications XX. Proc. SPIE, 2009, 7237, 72370M.

14. Mon-Williams, M. and Tresilian, J. R. Some recent studies on the extraretinal contribution to distance perception. Perception, 1999, 28(2), 167-181.

15. Naceri, A., Chellali, R. and Hoinville, T. Depth perception within peripersonal space using head-mounted display. Presence: Teleoperators Virtual Environ., 2011, 20(3), 254272.

16. Page, D., Thomas, T., Kelley, S., Jones, P. G. and Miller, D. A. Vergence and accommodation in simulation and training with 3D displays. In Proceedings of Interservice/Industry Training, Simulation, and Education Conference 2014, 14147.

17. Livingston, M. A., Ellis, S. R., White, S. M., Feiner, S. K. and Lederer, A. Vertical vergence calibration for augmented reality displays. In Proceedings of IEEE Virtual Reality Conference, Alexandria, VA, USA, March 12-15, 2006, 287-288.

18. Rolland, J. P., Krueger, M. W. and Goon, A. Multifocal planes head-mounted displays. Appl. Opt., 2000, 39(19), 3209-3215. 
19. Zabels, R., Osmanis, K., Narels, M., Gertners, U., Ozols, A., Rutenbergs, K. and Osmanis, I. AR displays: Next-generation technologies to solve the vergence-accommodation conflict. Appl. Sci., 2019, 9(15), 3147.

20. Zhan, T., Xiong, J., Zou, J. and Wu, S.-T. Multifocal displays: review and prospect. PhotoniX, 2020, 1, 10.

21. Livingston, M. A., Ai, Z. and Decker, J. W. A user study towards understanding stereo perception in head-worn augmented reality displays. In Proceedings of 2009 8th IEEE International Symposium on Mixed and Augmented Reality, Orlando, FL, USA, October 19-22, 2009. IEEE, 53-56.

22. Bakeman, R. Recommended effect size statistics for repeated measures designs. Behav. Res. Methods, 2005, 37(3), 379-384.

23. Cohen, J. Statistical Power Analysis for the Behavioral Sciences. 2nd ed. Lawrence Erlbaum Associates, Hillsdale, NJ, 1988.

24. Ping, J., Weng, D., Liu, Y. and Wang, Y. Depth perception in shuffleboard: Depth cues effect on depth perception in virtual and augmented reality system. J. Soc. Inf. Disp., 2019, 28(2), 164-176.

25. Matsushima, E. H., Vaz, A. M., Cazuza, R. A. and Ribeiro Filho, N. P. Independence of egocentric and exocentric direction processing in visual space. Psychol. Neurosci., 2014, 7(3), 277-284.

26. Singh, G., Ellis, S. R. and Swan, J. E. The effect of focal distance, age, and brightness on near-field augmented reality depth matching. IEEE Trans. Vis. Comput. Graph., 2018, 26(2), 1385-1398.

27. Drascic, D. and Milgram, P. Perceptual issues in augmented reality. Proc. SPIE, 1996, 2653, 123-134.

28. Lin, C. J., Caesaron, D. and Woldegiorgis, B. H. The effects of augmented reality interaction techniques on egocentric distance estimation accuracy. Appl. Sci., 2019, 9(21), 4652.

29. Rousset, T., Bourdin, C., Goulon, C., Monnoyer, J. and Vercher, J.-L. Misperception of egocentric distances in virtual environments: More a question of training than a technological issue? Displays, 2018, 52, 8-20.

30. Eckert, M., Volmerg, J. S. and Friedrich, C. M. Augmented reality in medicine: Systematic and bibliographic review. JMIR Mhealth Uhealth, 2019, 7(4), e10967.

31. Uppot, R. N., Laguna, B., McCarthy, C. J., De Novi, G., Phelps, A., Siegel, E. and Courtier, J. Implementing virtual and augmented reality tools for radiology education and training, communication, and clinical care. Radiology, 2019, 291(3), 570-580.

32. Douglas, D. B., Wilke, C. A., Gibson, J. D., Boone, J. M. and Wintermark, M. Augmented reality: Advances in diagnostic imaging. Multimodal Technol. Interact., 2017, 1(4), 29.

33. O'Shea, R. P., Blackburn, S. G. and Ono, H. Contrast as a depth cue. Vision Res., 1994, 34(12), 1595-1604.

\title{
Liitreaalsuse ruumitaju võrdlev analüüs sõltuvalt sügavustunnuste kooskõlalisusest
}

\author{
Linda Krauze, Tatjana Pladere, Roberts Zabels, Rendijs Smukulis, Viktorija Barkovska, \\ Vita Konosonoka, Ibrahim Musayev, Aiga Svede ja Gunta Krumina
}

Vasturääkivused sügavustunnustes (akommodatsioon ja vergents) on üheks peamiseks tunnuseks stereoskoopilise liitreaalsuse tajumisel lühikestelt distantsidelt. Mõjutatakse mitte ainult kasutajamugavust, aga ka ruumilisi otsustusi. Eri distantsidelt pildistatud kaasuvate tunnustega kujutised on muutunud kättesaadavaks tänu multifokaalse arhitektuuri rakendamisele visiirkuvarites, aga selle mõju ruumitajule on vähe uuritud. Selles psühhofüüsikakatses uuriti kooskõlaliste ja vastukäivate sügavustunnuste mõju stiimulite tajutud kaugusele, kasutades stereoskoopilist pähe paigaldatava liitreaalsuse komplekti ekraani, mis töötas mono- või multifokaalses esitlusviisis. Katseisikud määrasid objektide distantsi, mida näidati kolmelt vaatekauguselt $(45 \mathrm{~cm}, 65 \mathrm{~cm}$ ja $115 \mathrm{~cm})$. Statistiliselt olulisi erinevusi objektide kauguse määramise täpsusel kui stiimuleid esitati vastukäivalt, aga kui stiimuleid esitati kooskõlaliselt, siis oli katseisikute sooritus kiirem. Uuringu tulemused osutavad, et multifokaalse esitusviisi kasutamisel vahendavad kooskõlalised sügavustunnused kiiremaid otsustusprotsesse stiimulite ruumisuhete määratlemisel liitreaalsuses. Liitreaalsuse edasine tehnoloogiline areng peaks parandama otsustusprotsesside täpsust ruumisuhete hindamisel. 